\title{
Erratum: Book Reviews
}

In the 12(1), Spring 1989 issue of Qualitative Sociology, Rosanna Hertz's name and affiliation, Harvard Medical School, were inadvertently omitted at the end of her Book Reviews of The Regulation of Sexuality: Experiences of Family Planning Workers by Carole Joffe, Bitter Choices: Blue-Collar Women in and out of Work by Ellen Israel Rosen, and Journey into Sexuality: An Exploratory Voyage by Ira L. Reiss. 